\title{
PERCEPÇÃO DE MEMBROS DE ASSOCIAÇÕES ATLÉTICAS ACADÊMICAS UNIVERSITÁRIAS EM RELAÇÃO AO PLANEJAMENTO E CONTROLE GERENCIAL
}

\author{
${ }^{1}$ Eloah Exmalte De Castro Aguiar \\ ${ }^{2}$ Wesley Cirino dos Santos
}

\section{Resumo}

Objetivo: O objetivo geral desta pesquisa é analisar a percepção e as práticas de controle gerencial dos diretores das Associações Acadêmicas Atléticas (AAA) universitárias.

Método: De caráter descritivo, a pesquisa foi segmentada em uma revisão da literatura e, em seguida, foi apresentado a percepção e as práticas de controle gerencial dos diretores das AAA, realizado por meio de um survey eletrônico semiestruturado, endereçado a diferentes áreas das associações. À abordagem do problema caracteriza-se pelo emprego de quantificação no tratamento das informações por meio de análise estatística.

Originalidade/Relevância: Tendo em vista o escasso número de estudos desenvolvidos acerca do tema, ele apresenta até então pouca aplicabilidade na área esportiva. Desta forma, ganha relevância esta pesquisa, diante da capacidade desta para a contribuição e o aprofundamento do assunto.

Resultados: Por meio de análise de estatística descritiva, destacam-se como problemas identificados à comunicação da informação financeira, da entrada e saída de caixa, dos responsáveis pelo controle financeiro e da maneira como as receitas são angariadas e os custos são gastos. Ademais, identificou-se que a percepção dos membros das AAA sobre o controle gerencial é que este é incipiente frente à necessidade de métodos de gestão que são aplicados em suas associações.

Contribuições teóricas/metodológicas: Evidencia os pontos do estágio atual do planejamento e controle gerencial das Associações Atléticas Acadêmicas em diferentes cursos de graduação no Estado de Minas Gerais e a percepção dos estudantes em relação à temática de estudo.

Palavras-chave: Controle Gerencial. Associações Acadêmicas Atlética. Ferramentas gerenciais.

\footnotetext{
${ }^{1}$ Universidade Federal de Minas Gerais - UFMG, Minas Gerais, (Brasil). E-mail: eloahdecastroa@gmail.com Orcid id: https://orcid.org/0000-0002-3616-5136

${ }^{2}$ Universidade Federal de Minas Gerais - UFMG, Minas Gerais, (Brasil). E-mail: wcsantos104@gmail.com Orcid id: https://orcid.org/0000-0003-3041-9825
} 


\title{
UNIVERSITY ATHLETIC ACADEMIC ASSOCIATIONS MEMBERS' PERCEPTION IN RELATION TO MANAGEMENT PLANNING AND MANAGEMENT CONTROL
}

\begin{abstract}
Objective: The main objective of this research was to analyze perception and practices of management control of the directors of universities Academic Athletic Associations (AAA).

Methodology / approach: Descriptive, the research was segmented in a literature review and then presented the perception and management control practices of AAA directors, conducted through a semi-structured electronic survey, addressed to different areas of the associations. The approach to the problem is characterized using quantification in the treatment of information through statistical analysis.
\end{abstract}

Originality/ Relevance: Given the low number of studies developed in the area, it has not much applicability at the sports area. Thus, this research gains relevance, given its ability to contribute and deepen the subject.

Main results: Through analysis of descriptive statistics, the following stand out as problems identified in the communication of financial information, cash inflows and outflows, those responsible for financial control and the way revenues are raised and costs are spent. Thus, it was identified that the AAA members perception about managerial control is that it is incipient in the face of the need for management methods that are applied in their associations.

Theoretical / methodological contributions: It highlights points of the current stage of planning and management control of Academic Athletic Associations in different undergraduate courses in the State of Minas Gerais and the students' perception regarding the subject of study.

Keywords: Management control. Academic Athletic Associations. Management tools. 


\section{PERCEPCIÓN DE LOS MIEMBROS DE LAS ASOCIACIONES ACADÉMICAS ATLETICAS UNIVERSITARIAS EN RELACIÓN CON LA PLANIFICACIÓN Y EL CONTROL DE LA GESTIÓN}

\section{Resumen}

Proposito del estudio: El objetivo principal de esta investigación fue analizar la percepción y las prácticas de control de gestión de los directores de las universidades Asociación Académica Atletica (AAA).

Metodología / enfoque: El estudio fue descriptivo, la investigación fue segmentada en una revisión de literatura y luego presentó las prácticas de percepción y control de gestión de los directores de AAA, realizadas través de una encuesta electrónica semiestructurada, dirigida a diferentes áreas de las asociaciones. El enfoque del problema se caracteriza mediante la cuantificación en el tratamiento de la información a través del análisis estadístico.

Originalidad / Relevancia: Dado el bajo número de estudios desarrollados en área, tiene poca aplicabilidad en la área deportiva. Por lo tanto, esta investigación gana relevancia, dada su capacidad para contribuir y profundizar el tema.

Resultados principales: A través de análisis de estadísticas descriptivas, destacan como problemas identificados en la comunicación de información financiera, entradas y salidas de efectivo, los responsables del control financiero y la forma en que se obtienen los ingresos y se gastan los costos. Por lo tanto, se identificó que la percepción de los miembros de las AAA sobre el control gerencial es que es incipiente ante la necesidad de métodos de gestión que se aplican en sus asociaciones.

Contribuciones teóricas / metodológicas: Destaca los puntos de la etapa actual de planificación y control de gestión de las Asociaciones Académicas Atléticas en diferentes cursos de pregrado en Estado de Minas Gerais y la percepción de los estudiantes sobre el tema de estudio.

Palabras clave: Control de administración. Asociaciones atléticas académicas. Herramientas de gestión. 


\section{Introdução}

Tendo ciência da importância do esporte universitário educacional, surgem as Associações Atléticas Acadêmicas (AAA), que são organizações esportivas, geridas por estudantes, responsáveis por promover e coordenar a prática esportiva universitária em todo o país, sendo responsáveis pela oferta de treinamentos, campeonatos e eventos esportivos, contemplando atividades coletivas e individuais, buscando abranger o maior número de alunos por meio de suas atividades. Além da dimensão esportiva, essas associações são, em grande parte, responsáveis pela integração e interação dos alunos da universidade por meio da organização de eventos (Oliveira, 2016).

Para Ribeiro e Marin (2012), o esporte universitário é tido como um instrumento de educação e socialização. Esses autores enfatizam que o incentivo à prática esportiva, além de complementar a formação acadêmica, auxilia no desenvolvimento social dos alunos, capaz de suprir demandas e necessidades de integração física, cultural e social de estudantes universitários. Nesse contexto, considerando a necessidade de contribuir para o ambiente acadêmico de forma a melhorar o espaço universitário, as AAA buscam, de diferentes maneiras, encaixar-se em sua conjuntura social. Contudo, é necessária uma adequada gestão de seus recursos para sua sobrevivência nesse meio.

Identifica-se, então, a necessidade de um sistema de controle gerencial, visto que, apesar de serem consideradas entidades sem fins lucrativos, os conceitos relacionados a planejamento e controle são delimitados e identificados na rotina de atividades de associações como as AAA. Segundo Anthony e Govindarajan (2008), o controle gerencial pode ser compreendido como o processo pelo qual os gestores influenciam os outros membros da organização a implementar a estratégia corporativa. Segundo os autores, o controle gerencial envolve o planejamento e o controle, assim como requer a coordenação de indivíduos.

Neste cenário, busca-se compreender as percepções de universitários membros de AAA quanto à temática em análise, culminando na seguinte questão de pesquisa: qual a percepção e práticas dos membros das atléticas universitárias sobre o controle gerencial em suas Associações Atléticas? O objetivo do presente estudo consiste, portanto, em identificar a percepção e práticas dos membros das atléticas universitárias sobre o controle gerencial em AAA do Estado de Minas Gerais, a fim de identificar as práticas relacionadas ao controle gerencial normalmente realizadas e discutir possíveis aprimoramentos para o controle gerencial em associações atléticas universitárias.

Dessa forma, como contribuição, considerando a relevância que o assunto apresenta para as AAA, os achados da pesquisa contribuem para evidenciar os pontos do estágio atual do planejamento e controle gerencial das Associações Atléticas Acadêmicas em diferentes cursos de graduação no Estado de Minas Gerais e a percepção dos estudantes em relação à temática de estudo. Uma vez que, apesar da grande importância do Esporte Universitário e das AAA na vida dos universitários, é escasso número de estudos desenvolvidos acerca do tema - publicações em periódicos, dissertações e outros trabalhos - (Barbosa, 2014; Oliveira, 2016). Já em Minas Gerais, o conhecimento nas áreas mencionadas é ainda mais escasso, principalmente a respeito de atléticas. Não foi encontrado nenhum estudo sobre AAA publicado em MG, entretanto, este acontecimento pode se justificar pelo pouco tempo em que estas organizações estão presentes nas instituições de ensino superior. Isso posto, ganha relevância a pesquisa realizada, diante da capacidade desta para a contribuição e o aprofundamento do assunto.

\section{REFERENCIAL TEÓRICO}

\section{Planejamento e Controle Gerencial}

Segundo Frezatti (2015), planejar consiste em decidir antecipadamente o que deve ser feito. Enquanto o termo controle tem sido utilizado de maneira enfática, visto que, o que se pretende no ambiente organizacional é que a estratégia planejada seja de fato executada, ou seja, é o processo de acompanhar as atividades de uma empresa de modo a garantir que elas estejam consistentes com os planos e que os objetivos sejam alcançados. Sendo assim, a gestão da organização estabelece o sistema de planejamento e controle gerencial, entendido como o processo de direcionar organizações rumo a padrões viáveis de atividade em um ambiente caracterizado por incertezas.

Por conseguinte, controle gerencial cumpre um papel organizacional de proporcionar que gestores sejam capazes de influenciar o comportamento de outros membros organizacionais na direção de estratégias adotadas (Berry, Broadbent \& Otley, 2005; Anthony \& Govindarajan, 2008).

Para cumprir com seu papel organizacional, um 
sistema de planejamento e controle gerencial é elementos, a Figura 1 descreve, assim, o composto pelo relacionamento entre vários relacionamento entre os vários elementos.

Figura 1 - Relacionamento entre os elementos do processo de planejamento e controle gerencial

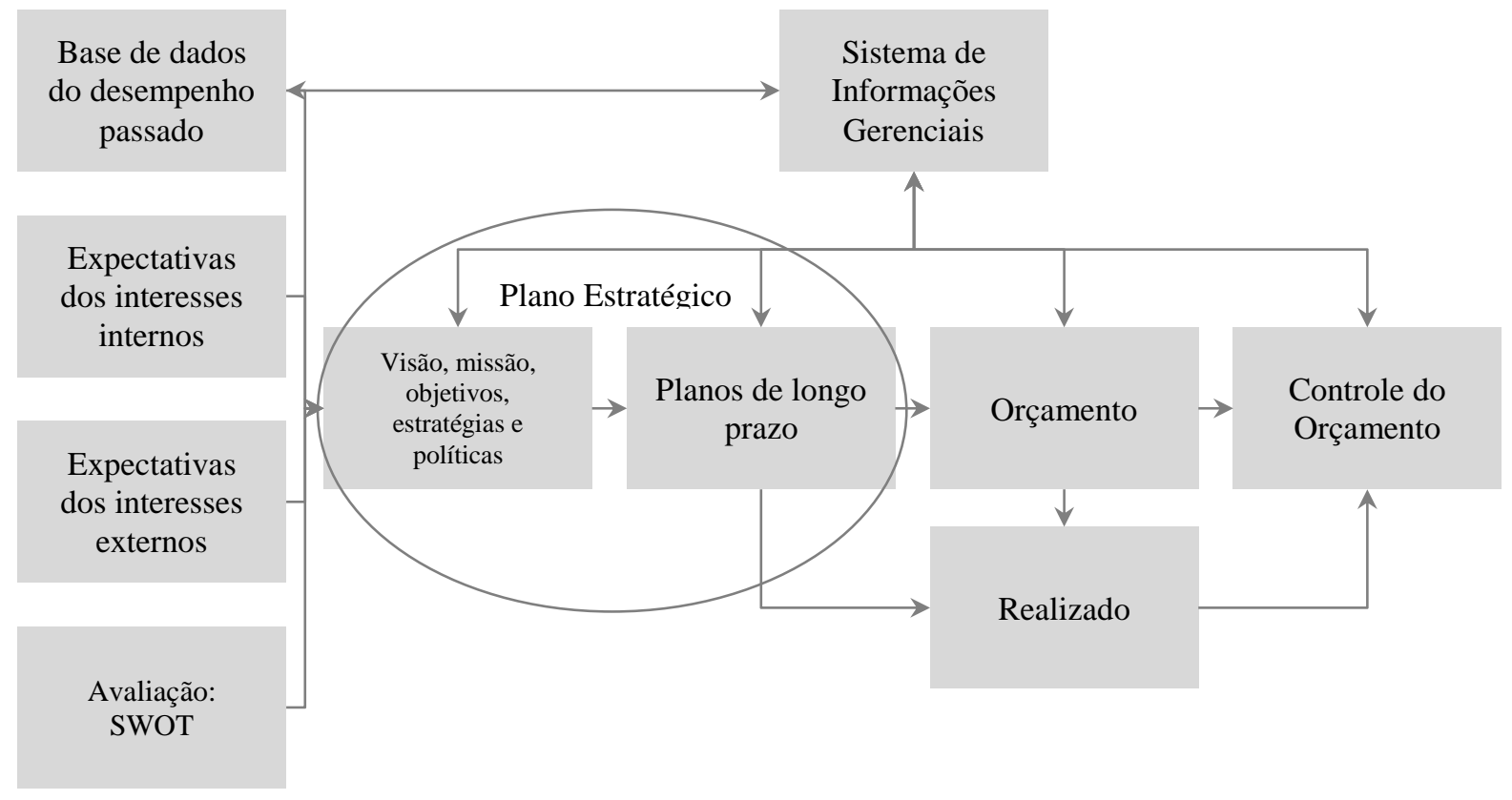

Fonte: Steiner (1979, p.17), adaptado por Frezatti (2015, p.14)

O sistema de relacionamento do processo de planejamento e controle gerencial envolve diferentes passos dos elementos de relacionamento, sendo eles: (i) base de dados com desempenho retrospectivo, possibilitando análises para o desenvolvimento de planejamento; (ii) expectativas de interesses internos e externos, cujo objetivo é maximizar a utilidade de ambos os agentes interessados; (iii) determinação de elementos estruturais do planejamento estratégico, proporcionando coerência de atitudes e consistências de longo prazo; e, por fim, (iv) desenvolvimento do planejamento, execução e controle orçamentário, cujo objetivo é monitorar o plano estratégico da organização no que se refere à sua parcela de curto prazo, servindo também para corrigir desvios e realimentar o processo de planejamento (Frezatti, 2015).

Dentre as ferramentas de planejamento controle gerencial, inicialmente a ênfase recaía no orçamento (Brownell, 1981; Merchant, 1981). Em seguida, outras técnicas foram analisadas, tais como sistemas de mensuração de desempenho e de incentivo (Abernethy \& Lillis, 1995; Govindarajan, 1984; Govindarajan \& Gupta, 1985), Activity Management (Gosselin, 1997) e Balanced Scorecard (Hoque \& James, 2000). Sendo assim, as ferramentas de gestão gerenciais, sejam tradicionais ou contemporâneas
(Chenhall \& Langfield-Smith, 1998; Ferreira \& Otley, 2006), são consideradas métodos que auxiliam na avaliação e organização empresarial. São capazes de aumentar potencialmente o desempenho de uma entidade, independente da forma de atuação ou porte.

Percebe-se, por meio da obra de Pinheiro (1996), que são poucas as empresas que utilizam tais recursos no país, principalmente ao tratar-se de empresas de pequeno porte, entretanto, aquelas que conseguem adotar práticas gerenciais desde o início são capazes de identificar, com maior facilidade, onde estão suas forças e fraquezas, montando uma empresa consolidada desde o início do processo de atuação. Observa-se também a necessidade de difundir métodos de controle de gestão para as atividades dessas empresas, buscando diferenciar-se dos demais concorrentes e garantir a sua continuidade.

\section{Gestão esportiva universitária}

\section{Gestão esportiva}

Segundo Bateman e Snell (1996), a gestão esportiva envolve todo um processo de integração de pessoas e recursos materiais para a realização de objetivos de organizações esportivas de maneira eficaz, ou seja, a aplicação dos princípios de gestão a organizações esportivas. A gestão do esporte ainda 
pode ser considerada uma área de investigação acadêmica recente. A partir da metade da década de 1980, trabalhos com mais rigor científico começaram a ser publicados em periódicos específicos da área. Contudo, os primeiros programas acadêmicos de sport management foram criados nos Estados Unidos, no final da década de 1960, para atender demandas do esporte profissional e universitário americano (Rocha $\&$ Chelladurai, 2011).

Slack e Parent (2006) informam que uma organização esportiva é uma entidade social, com objetivos e limites claros e definidos, envolvida na indústria esportiva, seja essa indústria envolvida na produção de materiais esportivos, seja na gestão de equipes esportivas, seja em fatores que envolvem a possibilidade de entregar um produto esportivo.

Rocha e Chelladurai (2011, p. 318) afirmam que, "para se definir gestão do esporte a partir do conceito de organizações é preciso uma definição mais precisa do que compõe cada uma dessas organizações esportivas". Organizações esportivas têm como atividade principal a produção e marketing de serviços relacionados ao esporte (sentido amplo) para participantes ou espectadores. Para o autor, gestores esportivos deveriam conhecer o processo produtivo e estarem preparados para atuar em organizações esportivas, mas não necessariamente em organizações que usam o esporte para promover seus produtos.

Na conceituação da gestão esportiva, é identificada ligação com a parte de coordenação das atividades relacionadas à prática esportiva. O marketing e a produção são atividades também relacionadas com esta coordenação, sendo assim a gestão esportiva uma compreensão de todas as atividades da uma empresa na área.

\section{Esporte universitário e as AAA}

A relação entre o esporte e o Estado começou a se delinear já nas primeiras décadas do século XX. Hatzidakis (1993) afirma que o Esporte Universitário é um fenômeno social que procura suprir necessidades de intercâmbio e integração física, cultural e social dos universitários. É apresentado o conceito de uma forma ampla por não o limitar a simples prática de atividades físicas, uma vez que o ambiente universitário demanda os tópicos apresentados, como a integração e o intercâmbio cultural. Entretanto, é identificada uma forma de tratamento para o Esporte Universitário como um fenômeno social.

Em relação a estudos na área, Barbosa (2014) apresenta que são poucos os trabalhos voltados para o Esporte Universitário, bem como seus fundamentos e percepções sobre sua gestão. Mazzei e Bastos (2012) afirmam ainda que a temática mais abordada sobre o tema faz referência a sua história, conceitos e relação com o Estado. A escassez de estudos acerca da temática é referente tanto ao tema de gestão esportiva quanto ao tema Esporte Universitário.

Dentro do contexto do Esporte Universitário, como grandes representantes, apresentam-se as Associações Atléticas Acadêmicas (AAA). Conforme já mencionado, tratam-se de associações universitárias que possuem dois objetivos no ambiente acadêmico: promover o esporte universitário e promover a integração entre os alunos através do esporte. No dia 15 de setembro de 1941, o Decreto-Lei $\mathrm{n}^{\circ} 3.617$ passou a regulamentar a organização e 0 funcionamento do esporte universitário, determinando a base do funcionamento deste ecossistema. Após a aprovação da lei supracitada, Starepravo (2015) afirmam que a representação básica no esporte universitário brasileiro seria as AAA. A união destas nos estados, territórios e Distrito Federal formaria as federações de esporte universitário e estas, por sua vez, formariam, reunidas, a Confederação de Desportos Universitários.

\section{TIPOLOGIA DA PESQUISA}

Este estudo, de caráter descritivo (Gil, 2012), utilizou-se de fontes primárias para alcançar o objetivo de identificar a percepção e as práticas de controle gerencial dos membros das AAA. A amostra do estudo, de natureza convencional e não probabilística, foi composta por 40 estudantes matriculados em diferentes cursos de graduação, sendo 14 (quatorze) atléticas participantes da Liga das Atléticas da UFMG (LAU) e 3 (três) atléticas participantes da Liga das Atléticas de Gerenciais do Estado de Minas Gerais (LAGEMG).

Foram selecionados os membros que se encontravam, em sua maioria, em cargos diretivos e, obrigatoriamente, os Diretores Jurídico-Financeiro das associações, assim como os Presidentes e VicePresidentes (membros de maior grau hierárquico dentro da associação), esperava-se, dessa forma, que estes membros já possuir conhecimento suficiente acerca da temática em análise.

Destaca-se que as AAA e os membros entrevistados foram escolhidos mediante a utilização de critérios de acessibilidade, o que requer cuidados para a realização de inferências, tendo em vista que a população da qual a amostra foi selecionada pode ser substancialmente diferente. Desse modo, os 
resultados encontrados se restringem à amostra analisada, não podendo ser generalizados para a população, que envolve todos os estudantes participantes como membros de gestão das Associações Atléticas Acadêmicas no Brasil.

Em relação aos procedimentos de coleta de dados, optou-se pela aplicação de um questionário semiestruturado junto aos membros que exercem cargos de diretoria. Os respondentes tiveram acesso ao questionário eletrônico, aplicado virtualmente pelos pesquisadores. A realização da pesquisa deu-se também mediante o consentimento dos discentes, após os esclarecimentos de que a participação seria voluntária e o estudante poderia cancelar ou interromper sua participação a qualquer momento; e o anonimato do respondente seria garantido, de modo que não haveria riscos de que dados individuais fossem identificados. Os dados foram coletados durante os meses de maio e junho de 2018.

$\mathrm{O}$ instrumento utilizado consistiu em três partes: (i) apresentação geral da AAA, assim como a dos respondentes, hierarquia, conhecimentos gerais do ambiente em que é situada; (ii) dados referentes à questão financeira da associação, entre eles, renda média, gastos recorrentes, formas de entrada de receita; e (iii) descrição das práticas de controle gerencial utilizadas que não foram abordadas nas perguntas.

O questionário foi composto a partir de tópicos com a finalidade de verificar como os participantes das AAA compreendem o planejamento e controle gerencial de suas instituições, a percepção destes sobre a relevância de se praticar o tema, as diferentes formas de entradas de recursos, além de mensurar o grau de conhecimento dos respondentes acerca das atribuições de práticas gerenciais, dentre outras questões a serem detalhadas na análise dos resultados.

Por fim, alinhado com o objetivo principal da pesquisa, a análise dos dados foi realizada através de estatística descritiva, que mensurou os dados contidos no banco de dados de respostas, visando delinear o perfil dos respondentes e a percepção e prática dos discentes em relação ao planejamento e controle gerencial, e assim obter dados satisfatórios a serem considerados em futuras melhorias no processo de gestão das AAA.

\section{ANÁLISE DOS RESULTADOS}

\section{Caracterização do perfil dos respondentes}

Conforme já mencionado, a amostra do estudo foi composta por 40 estudantes pertencentes a Associações Atléticas Acadêmicas matriculados em diversos cursos de graduação do Estado de Minas Gerais, sendo 14 (quatorze) atléticas participantes da Liga das Atléticas da UFMG (LAU) e 3 (três) atléticas participantes da Liga das Atléticas de Gerenciais do Estado de Minas Gerais (LAGEMG).

Identificou-se, conforme Figura 2, que o principal objetivo das AAA, segundo os respondentes, é a integração dos membros do ambiente universitário (não apenas alunos, mas também a comunidade acadêmica, como professores e funcionários da Universidade), por meio do esporte e da promoção de eventos, buscando ser capaz de melhorar a saúde e o contexto social envolvido. Ressalta-se que, para membros dentro das associações, a gestão e os processos relacionados à rotina são vistos como um projeto, uma atividade pela qual eles trabalham, entregam resultados e possuem metas, buscando alcançar os objetivos propostos. Entende-se como membro todos aqueles responsáveis por levar as atividades da AAA para os outros afetados, como atletas.

Figura 2 - Nuvem de palavras sobre objetivo das AAA

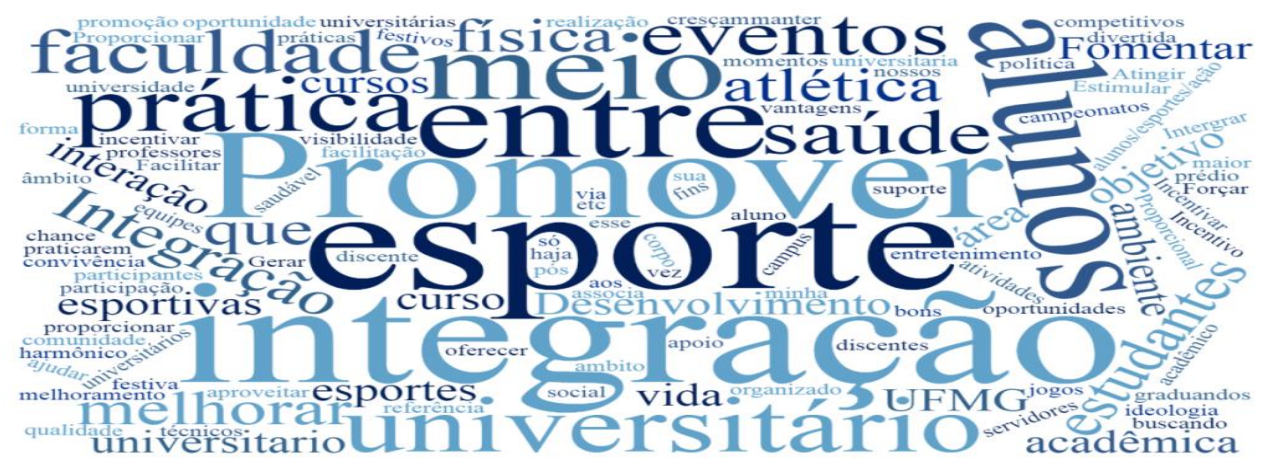

Fonte: Elaborado pelos autores 
Na Tabela 1, detalha-se o perfil dos respondentes.

Tabela 1 - Identificação dos respondentes

\begin{tabular}{|c|c|c|c|c|}
\hline & & Freq. & $\%$ & \% Acumulado \\
\hline \multirow{6}{*}{ Tempo de Participação } & De 1 mês a 6 meses & 6 & $15.00 \%$ & $15.00 \%$ \\
\hline & De 7 meses a 1 ano & 6 & $15.00 \%$ & $30.00 \%$ \\
\hline & De 1 ano a 2 anos & 16 & $40.00 \%$ & $70.00 \%$ \\
\hline & De 2 anos a 3 anos & 9 & $22.50 \%$ & $92.50 \%$ \\
\hline & Mais de 3 anos & 3 & $7.50 \%$ & $100 \%$ \\
\hline & Total & 40 & $100 \%$ & \\
\hline \multirow{9}{*}{ Cargo Ocupado } & Presidente & 11 & $27.50 \%$ & $27.50 \%$ \\
\hline & Vice Presidente & 4 & $10.00 \%$ & $37.50 \%$ \\
\hline & Diretor Administrativo/Financeiro/Jurídico & 6 & $15.00 \%$ & $52.50 \%$ \\
\hline & Diretor de Esportes & 4 & $10.00 \%$ & $62.50 \%$ \\
\hline & Diretor de Eventos e Logística/RH & 1 & $2.50 \%$ & $65.00 \%$ \\
\hline & Diretor de Marketing & 5 & $12.50 \%$ & $77.50 \%$ \\
\hline & Base/Assessoria & 8 & $20.00 \%$ & $97.50 \%$ \\
\hline & Prefiro não opinar & 1 & $2.50 \%$ & $100 \%$ \\
\hline & Total & 40 & $100 \%$ & \\
\hline \multirow{8}{*}{ Área de conhecimento } & Ciências Agrárias & 1 & $2.50 \%$ & $2.50 \%$ \\
\hline & Ciências Biológicas & 6 & $15.00 \%$ & $17.50 \%$ \\
\hline & Ciências Sociais Aplicadas & 16 & $40.00 \%$ & $57.50 \%$ \\
\hline & Ciências Educação & 2 & $5.00 \%$ & $62.50 \%$ \\
\hline & Ciências Exatas & 5 & $12.50 \%$ & $75.00 \%$ \\
\hline & Ciências Humanas & 5 & $12.50 \%$ & $87.50 \%$ \\
\hline & Ciências Saúde & 5 & $12.50 \%$ & $100 \%$ \\
\hline & Total & 40 & $100 \%$ & \\
\hline
\end{tabular}

Fonte: Elaborado pelos autores

Quanto tempo de participação na gestão das atléticas, a maioria dos membros possui de 1 a 2 dois anos (40\%) de gestão, seguido por membros de 1 a 12 meses (30\%) e $30 \%$ com mais de 2 anos. A análise da Tabela 1 permite verificar, também, que $77,5 \%$ dos respondentes assumem cargo de diretoria na gestão da AAA, sendo 15\%, Diretor Administrativo/Financeiro/Jurídico, diretamente responsável pelo controle gerencial. Finalmente, observa-se que, no tocante à área de conhecimento, $40 \%$ dos respondentes são estudantes de ciências sociais e aplicadas, $15 \%$ biológicas, $12,5 \%$ para as áreas de exatas, saúde e humanas, $5 \%$ educação e 2,5\% agrárias.

A delimitação do perfil do respondente permite: i) compreender se existe divergência na percepção de diretores de atléticas ligadas a cursos voltados para áreas gerenciais em relação a outras áreas, ou seja, o estudo busca verificar se há aplicabilidade no aprendizado desenvolvido dentro de sala de aula para a rotina da AAA; ii) analisar se os membros com mais tempo de gestão na Atlética possuem um melhor conhecimento dos processos de gestão financeira; e ,por fim, iii) se o cargo ocupado impacta na percepção sobre planejamento e controle gerencial.

\section{Análise da percepção dos membros das AAA em relação aos conceitos gerais de planejamento e controle gerencial}

A partir dos dados reportados, constatou-se que $60 \%$ dos respondentes entendem como objetivo financeiro da AAA a estabilidade financeira para cobrir gastos rotineiros, tais como pagamento de treinadores e compra de materiais esportivos para continuidade das atividades fim, contrapondo $14 \%$ das respostas indicam não haver nenhum objetivo financeiro. Observa-se que $21 \%$ dos respondentes apresentaram que o importante para a AAA é conseguir financiar competições para seus atletas, podendo ser compreendido como uma contrapartida para aqueles que sustentam as atividades das associações por meio de pagamento de mensalidades, por exemplo.

Em termos gerais, $75 \%$ das atléticas possuíam objetivos de longo prazo, sendo que, para alcance de tais objetivos, seria imprescindível a garantia de um bom controle, no mínimo, de saída de gastos. Dessa forma, é necessário que ela cresça e se organize como entidade, o que demandaria a aplicação de métodos de gestão. Dado o objetivo financeiro buscado pelas 
atléticas respondentes como continuidade das suas atividades e cobrir os gastos, buscou-se analisar entradas e saídas dentre um grupo pré-definido de itens. Em relação às receitas, esta foi dividida nas opções: (i) doação de ex- membros e membros; (ii) Eventos esportivos e festivos; (iii) mensalidade de treinos; (iv) patrocínio; (v) programa de associados; (vi) venda de produtos próprios; e (vii) venda de produtos externos/rifas. Dentre as opções, solicitou-se ainda que fossem definidas quais as receitas podem ser consideradas como fixas.

Identificou-se nessas questões que: (a) muitos dos respondentes não souberam reconhecer suas entradas de caixa fixas, ou seja, não souberam informar as receitas ou sua periodicidade; (b) A maioria das receitas apresentadas como fixas saem da venda de produtos e da mensalidade de treinos, como é de se esperar pelas atividades executadas pelas AAA e pelos objetivos apresentados anteriormente; (c) Das atléticas que informaram que acreditam que a AAA possui dificuldade financeira frequentemente, grande parte do peso de suas entradas está relacionada à execução de eventos festivos/ esportivos, que não possuem frequência fixa.

No que tange a esse último item, a atlética pode ficar sem fluxo de entrada nos meses que não sejam contemplados com tais eventos ou venda de produtos, uma vez que as respostas indicam que a venda destes só é executada se e quando existente demanda. Além disso, 70\% dessas atléticas não auferem (ou auferem com peso insignificante) receitas por meio de patrocínio e programas de associados, que são, para as outras atléticas, uma entrada de caixa que não gera muita saída, ou seja, deixam de receber um montante significativo para execução das atividades de rotina. Na Tabela 2, apresenta-se a distribuição dos pesos das entradas de caixa das AAA, informados nos dados acima.

Tabela 2 - Distribuição de pesos de entradas de caixa das AAA

\begin{tabular}{|l|c|c|c|c|c|c|c|c|}
\hline & Doação & Eventos & $\begin{array}{c}\text { Mensalidade } \\
\text { de treinos }\end{array}$ & Patrocínio & $\begin{array}{c}\text { Programa } \\
\text { de } \\
\text { Associados }\end{array}$ & $\begin{array}{c}\text { Vendas } \\
\text { de } \\
\text { produtos } \\
\text { externos }\end{array}$ & $\begin{array}{c}\text { Venda de } \\
\text { Produtos } \\
\text { Próprios }\end{array}$ & \begin{tabular}{c} 
Outros \\
\cline { 2 - 9 }
\end{tabular} \\
\cline { 2 - 9 } & $\mathbf{\%}$ & $\mathbf{\%}$ & $\mathbf{\%}$ & $\mathbf{\%}$ & $\mathbf{\%}$ & $\mathbf{\%}$ & $\mathbf{\%}$ & $\mathbf{\%}$ \\
\hline Entre 10\% e 25\% & $32.50 \%$ & $10.00 \%$ & $37.50 \%$ & $37.50 \%$ & $45.00 \%$ & $27.50 \%$ & $15.00 \%$ & $30.00 \%$ \\
\hline Entre 25\% e 50\% & $5.00 \%$ & $37.50 \%$ & $12.50 \%$ & $7.50 \%$ & $20.00 \%$ & $17.50 \%$ & $37.50 \%$ & $5.00 \%$ \\
\hline Entre 50\% e 75\% & $0.00 \%$ & $37.50 \%$ & $7.50 \%$ & $7.50 \%$ & $10.00 \%$ & $7.50 \%$ & $30.00 \%$ & $0.00 \%$ \\
\hline Entre 75\% e 100\% & $0.00 \%$ & $10.00 \%$ & $5.00 \%$ & $0.00 \%$ & $2.50 \%$ & $0.00 \%$ & $17.50 \%$ & $0.00 \%$ \\
\hline Sem peso significativo & $10.00 \%$ & $2.50 \%$ & $12.50 \%$ & $7.50 \%$ & $5.00 \%$ & $12.50 \%$ & $0.00 \%$ & $7.50 \%$ \\
\hline Não se aplica & $52.50 \%$ & $2.50 \%$ & $25.00 \%$ & $40.00 \%$ & $17.50 \%$ & $35.00 \%$ & $0.00 \%$ & $57.50 \%$ \\
\hline Total Geral & $\mathbf{1 0 0 \%}$ & $\mathbf{1 0 0 \%}$ & $\mathbf{1 0 0 \%}$ & $\mathbf{1 0 0 \%}$ & $\mathbf{1 0 0 \%}$ & $\mathbf{1 0 0 \%}$ & $\mathbf{1 0 0 \%}$ & $\mathbf{1 0 0 \%}$ \\
\hline
\end{tabular}

Fonte: Elaborada pelos autores

Ainda sobre os pesos das entradas das receitas nas respostas, identificou-se que a receita que possui peso mais significativo foi à venda de produtos próprios e as receitas provindas de eventos, como citado anteriormente. $\mathrm{O}$ que permite analisar na categoria de eventos que apesar de não serem consideradas necessariamente como fixa, entra com montantes altos, sendo capazes de mudar o cenário financeiro de uma AAA com um ou dois eventos dentro de um curto período de tempo. Por outro lado, a venda de produtos melhora não somente o fluxo financeiro da associação, mas amplia sua visibilidade e consolida sua marca, sendo assim reconhecida por aqueles produtos de fabricação própria, além do lucro que geram (63\% do público respondente informou que toda a precificação dos produtos ofertados baseia-se no custo do produto somado a uma margem de lucro).

Nessa categoria de pesos de entradas de caixa, identificou-se que existem duas que possuem capacidade de melhorar o fluxo de caixa mensal, devido à periodicidade de suas entradas, que são os programas de associados e as mensalidades de treinos. Entretanto, no que tange à mensalidade, 39\% dos respondentes das AAA informaram que não fazem nenhuma cobrança desta maneira aos atletas e $15 \%$ responderam que as entradas de mensalidade pesam abaixo de $25 \%$ da receita total da AAA. Esta última observação é explicada porque o número de atletas pagantes de mensalidade é de, em média, 30 atletas. Em relação ao programa de associados, $28 \%$ dos respondentes afirmaram não possuir planos de associação e $45 \%$ informaram que as entradas possuem peso abaixo de $25 \%$, encontradas também as quantidades de membros associados à AAA. Sendo assim, ainda que estas sejam entendidas como uma maneira de garantia de entrada fixa de caixa, não são 
opções hoje bem executadas pelas AAA, visto que dentre as que não possuem nem programa de associados e nem mensalidade de treinos, mais de $50 \%$, ao menos em partes, acredita que a associação possui dificuldades financeiras. Dentre as AAA da área de Sociais Aplicadas, identificou-se que apenas uma atlética não possui o programa de associação e nem a cobrança de mensalidades, tendo sua receita provinda de venda de produtos próprios.

Dentre as categorias de receitas a que possui menor peso é a Doação de ex-membros/ membros. Acredita-se que essa forma de arrecadação não deva ser levada em consideração em casos de análises de cenários possíveis dentro da associação, uma vez que não existe obrigatoriedade, nem frequência para a realização dessa receita dentro das AAA, sendo realizadas apenas quando existe interesse por parte do membro/ex-membro de executá-la.

Sobre a disponibilização de produtos e sua precificação, pôde-se verificar que, apesar de apresentados como receitas fixas, a maioria das atléticas não possui produtos estocados para venda $\mathrm{e}$ só realizam a venda diária por encomenda do público. Pelo número de respostas analisadas, é possível identificar que as AAA estudadas não possuem fluxo de caixa suficiente para manter seus estoques com uma quantidade alta de produtos, uma vez que isso significa que estas precisariam do recurso previamente, o que demonstra que as entradas de caixa não são constantes.

Em relação ao controle de caixa e seus responsáveis, identificou-se que, $36 \%$ das respostas, a movimentação de caixa é controlada exclusivamente pela célula financeira, como esperado. Entretanto, a presidência e as outras diretorias aparecem com um percentual representativo (30\%). Assim, dificulta-se o processo de controle do fluxo de caixa, visto que, em $25 \%$ dos casos, a associação utiliza de contas bancárias dos próprios membros para recebimentos e pagamentos e apenas em $20 \%$ dos casos as contas utilizadas são apenas de membros da área financeira.

Destaca-se que apenas $20 \%$ dos respondentes informaram que a atlética possui conta bancária própria. Obteve-se próxima porcentagem quando questionado se a atlética aceita pagamentos apenas em dinheiro, o que, se não houver um controle físico/ informatizado gera uma facilidade muito grande de perda de informação. Isso ocorre porque transações feitas em dinheiro não podem ser rastreadas, aumentando ainda mais a necessidade de um bom controle de caixa. Para AAA das áreas de sociais aplicadas, identificou-se que a porcentagem de concentração da movimentação na célula financeira chega a ser de $65 \%$ contra $58 \%$ do montante total de respostas analisadas, o que transparece uma melhor definição de atividades por cargo/célula. Entretanto, as contas pessoais de outros diretores também são utilizadas nessa base específica, o que pode prejudicar o processo de concentração de gastos/receitas.

Em relação aos gastos executados pelas AAA, identificou-se que, em sua maioria, são gastos com valores monetários baixos, mas com frequências altas. $\mathrm{Na}$ Figura 3, apresenta-se a distribuição informada dos principais gastos, independente de sua frequência.

Figura 3 - Distribuição de gastos executados pelas AAA

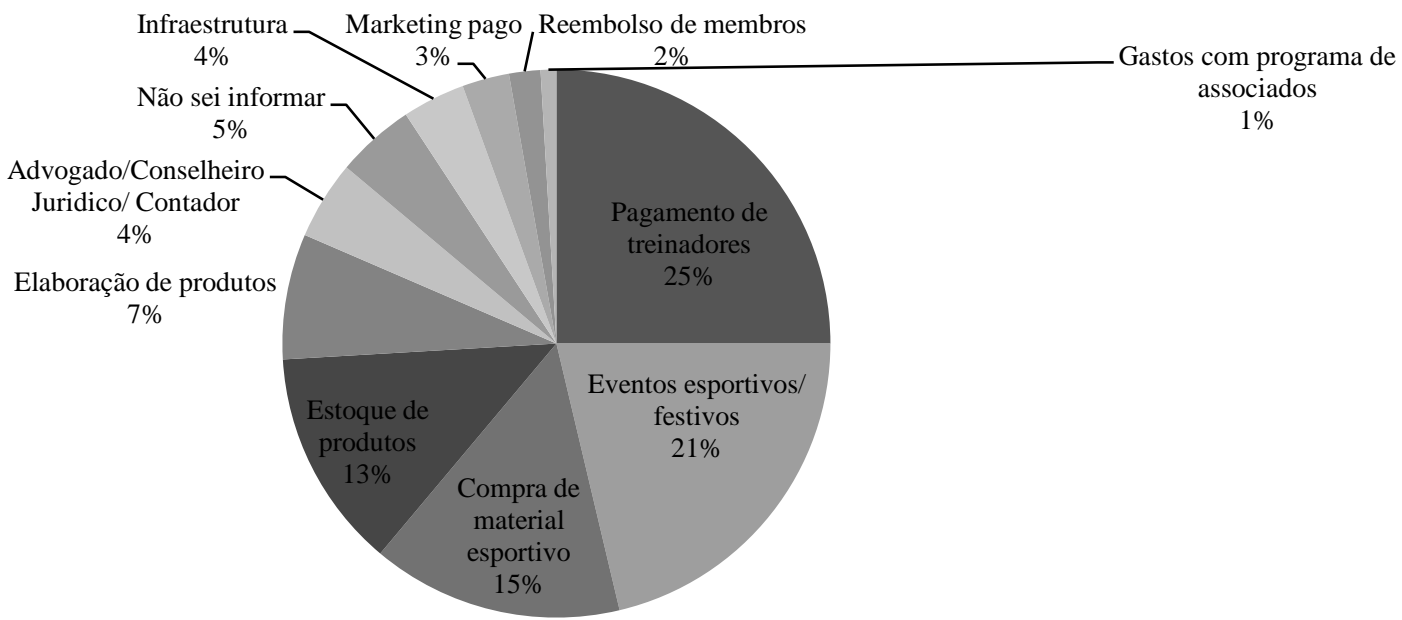

Fonte: Elaborada pelos autores

Observa-se, que o gasto que abrange a maior quantidade de respostas, correspondendo a $25 \%$ das 
respostas, trata-se do pagamento aos treinadores. Constatou-se também que este gasto possui frequência mensal. Dessa forma, é possível identificar que apesar de nem todas as AAA possuírem entradas mensais de caixa, em sua maioria há saídas mensais, podendo assim gerar um fluxo financeiro negativo, acumulando dívidas. Entretanto, os gastos apresentados mostram-se indispensáveis para a continuidade das atividades fim das associações, que, como apresentados anteriormente, buscam integrar por meio da prática esportiva, assim como a compra de material esportivo.

Além disso, outro gasto importante realizado para a atlética, que gera receitas frequentemente são os de estoques de produtos (13\% das respostas). Diferentemente dos gastos apresentados anteriormente, são gastos de montantes altos de, mas com retorno praticamente garantido e de forma quase imediata, uma vez que os produtos são comprados, em sua maioria, por encomenda (público paga $50 \%$ do valor total do produto antes de recebê-lo).

Os dados apresentados anteriormente se mostram preocupantes. Nesse sentido, quando questionados sobre a capacidade de pagamento das AAA, ou seja, se os respondentes acreditam que as entradas de dinheiro da atlética são suficientes para realizar todas as atividades que precisam ser feitas, considerando um período de um mês. Constatou-se que apenas $28 \%$ dos respondentes acreditam que a associação conseguiria cobrir todas as atividades com as entradas, enquanto $47 \%$ apresenta que são necessárias atividades não planejadas inicialmente para cobrir todos os gastos executados. Já $25 \%$ dos inquiridos indicaram a utilização do fluxo positivo de caixa para cobrir os gastos extras, o que pode prejudicar as disponibilidades pouco a pouco, gerando assim um possível prejuízo no longo prazo para a AAA.

Entretanto, esse tipo resposta condiz com outras respostas apresentadas no questionário, como sobre a forma como os gastos são planejados. Observou-se que apenas $40 \%$ dos respondentes indicaram que seria necessário garantir a capacidade de pagamento antes da execução do gasto; enquanto para os outros $60 \%$, o gasto pode ser executado sem planejamento/ orçamento prévio, para só então ser definida como a obrigação será quitada, dependendo de seu valor e periodicidade. Além disso, apenas $15 \%$ dos respondentes indicou que existe um planejamento financeiro para determinado período e $73 \%$ afirmaram que os orçamentos são desenvolvidos somente se houver necessidade e demanda por parte de alguma atividade ou interesse específico, como novos produtos ou projetos de parceria/patrocínio.
Contudo, não são todas as AAA que conseguem identificar seus gastos e nem mesmo saber como foram alocados. Dentre as respostas, apenas $45 \%$ dos respondentes afirmaram possuir capacidade de separar todos seus gastos por atividade que foi executada. Dentre o restante, $37 \%$ consegue identificar em partes, o que não possui boas aplicações, pois não há gestão dos gastos que não forem identificados. Desta forma, se o gasto não for identificado, não será possível utilizá-lo como dado para definição de melhores investimentos ou de priorização de gastos em futuros cenários, uma vez que não se entende sua necessidade ou caracterização. Isso se mostra ainda mais preocupante, visto que nas questões anteriores informou-se que, em grande parte das AAA, as entradas financeiras não são concentradas em uma só conta bancária e nem mesmo em uma só pessoa, sendo assim fácil ocorrer perdas de recursos e problemas de diferenciação entre o que é próprio e que é da associação.

Salienta-se que nas associações onde existe o controle financeiro, apenas $28 \%$ delas não são disponibilizados os dados financeiros para os outros membros da AAA seja para cobrança, para análise de viabilidade de projetos futuros ou apenas para gestão contínua do caixa. Entretanto, para 13\% das AAA, os gastos são acompanhados em papéis, não em vias digitais, sendo este um método precário, visto que existe a possibilidade de perda de tais materiais e a sua disponibilização ocorre apenas em reuniões e momentos compartilhados.

É importante ressaltar que as informações apresentadas nestas planilhas/ relatórios só poderiam ser transparentes e verificáveis, apresentando dados verídicos se os valores puderem ser identificados de acordo com sua atividade fim, mostrando assim a necessidade de um melhor controle de entradas e saídas de caixa. Dentre as respostas, 58\% dos respondentes afirmaram confiar nos resultados repassados pela célula financeira, conseguindo utilizar, dessa forma, os dados disponibilizados para melhoria das atividades executadas, capazes de gerar subsídios adequados para fundamentar boas decisões financeiras para a Atlética.

\section{CONSIDERAÇÕES FINAIS}

Este estudo teve como objetivo principal identificar a percepção e as práticas dos membros da AAA em relação à relevância do controle gerencial em associações atléticas universitárias do Estado de Minas Gerais. Para a concretização da pesquisa, foram aplicados questionários junto a estudantes 
pertencentes a Associações Atléticas Acadêmicas matriculados em diferentes cursos de graduação do Estado de Minas Gerais, sendo 14 (quatorze) atléticas participantes da Liga das Atléticas da UFMG (LAU) e 3 (três) atléticas participantes da Liga das Atléticas de Gerenciais do Estado de Minas Gerais (LAGEMG). Durante a realização da revisão da literatura, foi possível observar a escassez de trabalhos sobre o tema cujo foco se limitasse a Associações Atléticas Acadêmicas, de modo que a maior parte dos estudos eram relativos à gestão esportiva e ao planejamento e controle gerencial.

Conforme detalhado na análise de resultados, constataram-se problemas e dificuldades no modelo de gestão aplicado às AAA em análise, como também necessidades que, talvez, essas associações nem estejam cientes para melhoria de resultados. De maneira geral, pode-se inferir que os problemas existentes culminaram na resposta à pergunta final do questionário aplicado, pois quando questionados se acreditavam que a AAA passa por dificuldades financeiras frequentemente, apenas $28 \%$ dos respondentes afirmaram que não.

Por meio da análise dos dados empíricos, constataram-se as seguintes informações consideradas mais relevantes:

- A percepção dos membros das AAA, salvo responsáveis diretos pelo fluxo financeiro, sobre o controle gerencial é que este é incipiente frente à necessidade de métodos de gestão que são aplicados em suas associações.

- $\quad 72 \%$ dos respondentes acreditam possuir, ao menos em partes, dificuldades financeiras com frequência.

- Não há práticas de controle gerencial, controle de informações e definição de processos. Na maioria das respostas, os membros não souberam informar como funciona todo o fluxo financeiro dentro da AAA.

- A maioria das AAA não possuem contas bancárias próprias, o que demanda um controle ainda maior de gastos e receitas a fim de se evitar o conflito patrimonial.

- Práticas e ferramentas gerenciais, como por

\section{REFERÊNCIAS}

Abernethy, M. A., \& Lillis, A. M. (1995). The impact of manufacturing flexibility on management control system design. Accounting, Organizations and Society, 20(4), p. 241-258.

Anthony, R. N., \& Govindarajan, V. (2008). Sistemas de Controle Gerencial. São Paulo: McGrawHill. exemplo, a gestão de fluxo de caixa, não tem sido adotada por grande parte das atléticas estudadas, demonstrando dessa forma, fatores que apontam para a falta de estruturação dessas organizações.

Percebe-se, também, que o controle gerencial das Atléticas abordadas no estudo ainda se encontra em fase de estruturação. É importante ressaltar que, para as AAA de áreas de sociais aplicadas, identificou-se um conhecimento superior dos dados do que as demais. Entretanto não necessariamente esse conhecimento se transformou em aplicação prática de conceitos e metodologias. Assim, é necessário que não apenas se conheça o cenário geral da AAA, mas também que se consiga modelar estas metodologias para que sejam possíveis de aplicação e para que sejam capazes de auxiliar para que os membros consigam compreender o cenário financeiro da organização.

Todavia, em seu conjunto, as análises realizadas apresentam importantes limitações que precisam ser consideradas na interpretação dos dados: a pequena amostra analisada e selecionada por conveniência, e a não empregabilidade de estatística inferencial para análise dos dados. Mostra-se necessária também ampliação dos estudos na área, buscando compreender, como apresentado acima, novos modelos de aplicação de metodologias e práticas de gestão em tais ambientes específicos, visto que suas características como associação dificulta a aplicação de qualquer metodologia. Para pesquisas futuras, sugere-se o estudo das formas como as associações que não possuem entradas fixas são capazes de manter suas atividades, assim como quais os gastos deveriam ser priorizados para melhoria dos resultados gerados e ainda quais são (ou se existem) impactos da capacidade e do conhecimento de gestão financeira nos resultados esportivos das associações, entre outros. Mostra-se abrangente à área de estudos, visto à necessidade de melhoria no aspecto de gestão das associações, como apresentado neste trabalho.

Araújo, D. S. M. S. D., \& Araújo, C. G. S. D. (2000). Aptidão física, saúde e qualidade de vida relacionada à saúde em adultos. Revista brasileira de medicina do esporte, 6(5), 194-203.

Atkinson, A. A., Kaplan, R. S., Matsumura, E. M., \& Young, S. M. (2015). Contabilidade Gerencial: informação para tomada de decisão e execução da estratégia. São Paulo: Atlas. 
Barbosa, C. G. (2014). Liderança na gestão do esporte universitário: proposta da criação de uma rede de dados. Dissertação de Mestrado, Universidade Estadual Paulista, Instituto de Biociências de Rio Claro.

Bateman, T. S., \& Snell, S. (1996). Management: Building competitive advantage. Chicago: Irwin/McGraw-Hill.

Berry, A. J., Broadbent, J., \& Otley, D. (2005). Management control: theories, issues and performance. New York: Palgrave Macmillan.

Brownell, P. (1981). Participation in budgeting, locus of control and organizational effectiveness. The Accounting Review, 56(4), p. 844-860.

Chelladurai, P. (1994). Sport management: Defining the field. European Journal for Sport Management, 1(1), 7-21.

Chenhall, R. H., \& Langfield-Smith, K. (1998). The relationship between strategic priorities, management techniques and management accounting: an empirical investigation using a systems approach. Accounting, Organizations and Society, 23(5), 243-264.

Crepaldi, S. A. (2009). Curso básico de contabilidade de custos. Atlas.

Ferreira, A., \& Otley, D. (2006). Exploring inter and intra-relationships between the design and use of management control system. [Working Paper Series], Social Science Research Network, Recuperado em 15 março, 2006, de http://ssrn.com/abstract=896228

Franchi, K. M. B., \& Montenegro, R. M. (2012). Atividade física: uma necessidade para a boa saúde na terceira idade. Revista Brasileira em Promoção da Saúde, 18(3), p. 152-156.

Frezatti, F. (2015). Orçamento Empresarial: Planejamento e Controle Gerencial . Editora Atlas SA.

Gil, A. C. (2012). Métodos e técnicas de pesquisa social. 6 a ed. Ediitora Atlas SA.

Gosselin, M. (1997). The effect of strategy and organizational structure on the adoption and implementation of Activity-Based Costing. Accounting, Organizations and Society, 22(2), p. 105- 122.

Govindarajan, V. A. (1984). Appropriateness of accounting data in performance evaluation: an empirical examination of environmental uncertainty as an intervening variable. Accounting, Organizations and Society, 9(2), p. 125-135.

Govindarajan, V. A., \& Gupta, A. K. (1985). Linking control systems to business unit strategy: impact on performance. Accounting, Organizations and Society, 10(1), p. 51-66.

Hatzidakis, G. (2006). Esporte Universitário. Atlas do Esporte no Brasil. CONFEF, Rio de Janeiro/RJ.

Hatzidakis, G. (1993). Perfil da atividade esportiva principal de atletas universitários participantes de competições esportivas universitária oficiais. Dissertação de Mestrado, UNIFEC, São Caetano do Sul.

Hoque, Z., \& James, W. (2000). Linking balanced scorecard measures to size and market factors: impact on organizational performance. Journal of Management Accounting Research, 12, p. 1-17.

Mazzei, L. C., \& Bastos, F. C. (2012). Gestão do esporte no Brasil: desafios e perspectivas. São Paulo: Ícone.

Merchant, K. A. (1981). The design of the corporate budgeting system: influences on managerial behavior and performance. The Accounting Review, 56(4), p. 813829.

Oliveira, G. D. (2016). Gestão Organizacional nas Atléticas: um estudo sobre gerenciamento das Associações Atléticas Acadêmicas do DF. 69 f. TCC (Graduação)-Curso de Administração, Departamento de Administração, Universidade de Brasília, Brasília.

Pinheiro, M. (1996). Gestão e desempenho das empresas de pequeno porte: uma abordagem conceitual e empírica. Tese de Doutorado em Administração, Faculdade de Economia, Administração e Contabilidade. São Paulo: Universidade de São Paulo

Pitts, B. G., \& Stotlar, D. K. (2002). Fundamentals of sport marketing. Morgantown: Fitness Information Technology.

Ribeiro, G. M., \& Marin, E. C. (2012). Universidades públicas e as políticas de esporte e lazer. Revista do Programa de Pós-graduação Interdisciplinar em Estudos do Lazer, 15(3).

Rocha, C.; \& Bastos, F. (2011). Gestão do Esporte: definindo a área. Revista Brasileira de Educação Física, 25, 91-103. 
Rocha, C. M., \& Chelladurai, P. (2011). Relationship between organizational support and performance of college coaches: a mediational model. European Sport Management Quarterly, 11(3), 301-319.

Silva, C. L. (2017). Gestão estratégica de custos: o custo meta na cadeia de valor. Revista da FAE, 2(2).

Slack, T., \& Parent, M. M. (2006). Understanding sport organizations: the application of organizational theory. Champaign: Human Kinetics.

Starepravo, F. A. (2005). O esporte universitário paranaense e suas relações com o poder público. Dissertação de Mestrado em Educação Física, Departamento de Educação Física, Universidade Federal do Paraná, Curitiba. 